\title{
Papers
}

\section{Determinants of distribution channel choice for online software license purchases: A theoretical model}

\begin{abstract}
Pierre Hadaya
is a professor in the Department of Management and Technology at the École des Sciences de la Gestion de I'Université du Québec à Montréal. He holds a PhD in Management of Technology from the École Polytechnique de Montréal. His main research interests lie at the intersection of information technology management, business strategy and interorganizational design.
\end{abstract}

\section{Dominique DeSerres}

holds a Master's degree from the Université de Sherbrooke in Electronic Commerce Management. His research interests relate to electronic commerce and software distribution.

Keywords: software, distribution channels, digital rights management, transaction cost analysis, electronic commerce, determinants

Abstract The digital nature of software products combined with the advent of the internet has allowed for the proliferation of a new software delivery option: the digital distribution of software. Unfortunately, the diffusion of this new software delivery option has also facilitated copyright infringement and the distribution of pirated content. In response to these threats, software publishers have started applying various copy protection solutions to trial versions to make it more difficult for nonlicense holders to gain full access to products beyond their evaluation periods. In an escalating effort, some software publishers are now using digital rights management (DRM) technologies (among the various other distribution options they provide to their customers) when distributing software products online. By casting the software distribution channel choice as a transaction cost analysis (TCA) problem, this research proposes a theoretical model to uncover the reasons why, when purchasing a software license for a product that is marketed using a "try-before-you-buy" strategy, consumers would select the physical distribution channel not tied to any DRM technologies (ie, CD-ROM) rather than the digital distribution channel that uses DRM technologies (ie, electronic software distribution through demo-unlock). Journal of Digital Asset Management (2008) 4, 354-371. doi:10.1057/dam.2008.30

Pierre Hadaya

Département de management et technologie,

Université du Québec à Montréal,

École des Sciences de la Gestion,

P.O. Box 8888,

Downtown Station,

Montreal,

Quebec, Canada H3C 3P8 Tel: + 15149873000 ext. 3850

Fax: + 1-514-987-0360

E-mail: hadaya.pierre@

uqam.ca

web page: www.

professeurs.uqam.ca/

pages/hadaya.pierre.htm

\section{INTRODUCTION}

Before the 1990s, physical distribution through retailers and mail order houses - was the only option available to software publishers for delivering their products to consumers. Indeed, the software license acquisition process required the purchase of a tangible medium (eg, floppy disk, CD-ROM) from which the software product was installed. In today's digital economy, this limitation does not exist, as the digital nature of software products combined with the advent of the internet has allowed for the proliferation of a new software delivery option: the digital distribution of software. As the name indicates, this delivery option forgoes the physical distribution of tangible mediums and instead delivers software products electronically to customers.

Software publishers seized the opportunity and began developing "try-before-you-buy" marketing strategies, which gave potential customers the possibility to download and install trial versions of software products via the internet in order to test them on their 
computers first-hand before making a purchasing decision. The availability of these legal trial versions has, however, also facilitated copyright infringement and the distribution of pirated content. In response to this threat, ${ }^{1}$ industry wide initiatives were introduced to reduce software piracy rates around the world and their effects on software publishers' revenues. One of these anti-piracy measures consists in applying copy protection solutions to trial versions, thus making it more difficult for nonlicense holders to gain full access to products beyond their evaluation periods. In an escalating effort, software publishers are relying on increasingly advanced copy protection solutions to the point where some now use digital rights management (DRM) technologies when distributing software products online. The Association of American Publishers ${ }^{2}$ defines DRM as: "the technologies, tools, and processes that protect intellectual property during digital content commerce."

Despite the benefits they provide to software publishers, the diffusion of DRM technologies remains fairly limited, as consumers remain reluctant to adopt these innovations. For example, there is considerable debate raging today about the use of DRM technologies in the music and movie industries, as some argue the fairness to impose DRM technologies on consumers and others debate the issue of content ownership: whether a transfer of ownership occurs after content is purchased or whether that content is only licensed. Bradbury summarizes this problematic as follows: "As the battle drags on, it is becoming clear that DRM is not a technological issue alone: it sits along a complex continuum involving legal, political and economic considerations. No wonder, then, that this is proving such a difficult hurdle for distributors and consumers

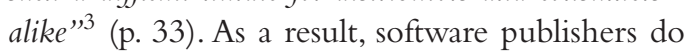
not generally require their client base to use distribution channels that rely on DRM technologies. Rather, they tend to offer a variety of software delivery options tied to different protection mechanisms.

Much has been written on the subject of DRM in the nonpeer-reviewed literature, but empirical research on the subject remains scarce. Fetscherin ${ }^{4}$ is among the few authors to have conducted research on the subject. He looked at consumers' perceptions towards the use of DRM in legal movie downloads. His findings showed that consumers most object to the use of encryption mechanisms and to the imposed use of specific software or hardware components to access digital content (essentially DRM technologies). His empirical study also showed that respondents rated restrictions through time limits and access frequency limits as those that would most likely keep them from downloading movies legally.

To partially address this gap in the literature, this research proposes a theoretical model to identify the factors that encourage consumers to select one of two software distribution channels, namely physical distribution not tied to any DRM technologies (ie, CD-ROM) or digital distribution that uses DRM technologies (ie, ESD through demo-unlock). To attain this objective, we cast the choice of a software distribution channel as a transaction cost analysis (TCA) problem. Indeed, according to Williamson, "virtually any relation, economic or otherwise, that takes the form of or can be described as a contracting problem can be evaluated to advantage in transaction cost economics terms" ${ }^{5}$ (p. 387). As such, the TCA framework is particularly well suited for this research because software users do not actually own the software product after making a purchase. Rather, they purchase a license for its use and remain tied to a certain extent to the owner of the intellectual property, the software publisher, for as long as they use the product. Therefore, the choice between channels does not involve technological considerations alone but also contracting issues.

In order to test the entire TCA model rather than only the link between transaction dimensions and governance model, the proposed theoretical model will simultaneously measure transaction costs and transaction dimensions as suggested by Rindfleisch and Heide ${ }^{6}$ Also, to take into account the entire software ownership lifecycle rather than focusing on a specific point in time, this research posits that two types of transactions may influence consumers' distribution channel choice. The first transaction relates to when customers purchase a license initially and the second to when license holders proceed with software reinstallations.

The remainder of the paper is organized as follows. The next section summarizes the relevant theoretical background tied to software 
distribution channels and TCA. Next, the research model and hypotheses are presented. An explanation of the research methodology is then provided. Finally, expected theoretical contributions are identified.

\section{THEORETICAL BACKGROUND}

\section{Software distribution channels and their piracy protection mechanisms}

Moores and Dhillon define software piracy as

"the unauthorized use, duplication, distribution or sale of commercially available software" 7 (p. 88). While several studies ${ }^{8-10}$ debate the best strategy to adopt in order to fight software piracy software, publishers in general do resort to using varying degrees of protection mechanisms.

According to Gopal and Sanders, ${ }^{11}$ software publishers generally rely on two types of controls to fight software piracy: (1) deterrent controls and (2) preventive controls. Deterrent controls take the form of dissuasion strategies meant to prevent piracy by reducing the number of attempts made to use pirated software. The threat of legal sanctions and broad education campaigns on the topic of piracy are prime examples of such controls. On the other hand, preventive controls use technological solutions in order to increase the economical cost of engaging in acts of piracy. Software-based copy protection mechanisms that make it harder and more time-consuming for nonlicense holders to gain full access to software are examples of preventive controls.

The following paragraphs present the two main software distribution channels used today by publishers, namely physical and digital distribution, as well as the protection mechanisms commonly used for each.

\section{Physical software distribution}

Consumers opting to install software products from a tangible medium will probably do so from a CD-ROM or a DVD-ROM, the two most frequently used physical formats today. They will likely purchase these products by either going to a conventional retail store (eg, Best Buy) or by ordering the same software package from a website (eg, Amazon). When distributing software this way, publishers can use various preventive controls.
At the least restrictive end of the spectrum, publishers can forgo using any protection mechanisms. In this case, license holders install software products from CD-ROMs and proceed with using them. Nonlicense holders only need to gain access to a copy of the original medium to proceed with their own installations. For a slightly more restrictive mechanism, publishers can rely on using serial numbers (or keys), schemes that are uniquely linked to specific CD-ROMs. When this preventive mechanism is used, license holders need to input the correct serial number before they can proceed with the software installation. In this case, nonlicense holders need to gain access to both the $\mathrm{CD}-\mathrm{ROM}$ and the serial number scheme to which it is linked in order to install the software product and use it.

Software publishers looking for more robust copy protection mechanisms may opt for solutions that limit one's ability to make physical copies of the source medium altogether. These mechanisms are relatively new to the marketplace and use software to limit computer hardware components (eg, CD-ROM writers) from making illegal copies of legitimate products. Software publishers looking for higher levels of piracy protection may require their customers to contact them in order to activate their license before they can start using it. When such processes are used, successful installation alone will not grant access to the product. The software must be activated by the provider before customers can use it. While software activation may be granted by contacting customer representatives by telephone, some publishers rely on a client-server activation process, which uses a DRM technology to activate their customers' license. Finally, publishers looking for maximum levels of protection can opt for solutions that use hardware keys, often referred as "dongles." Software protected this way will only grant access to its user if the accompanying dongle is plugged into the computer, or if the correct serial number that is displayed on it at a given time is inputted when loading the software product.

\section{Digital software distribution}

Software publishers can use three software distribution models to deliver their products to customers. The first digital software distribution model is "freeware." Software defined as freeware is available to download free of charge. 
While freeware developers may ask for donations, it is understood that the software product may be used free of charge. The second digital software distribution model is "shareware." Payment for software distributed this way is expected but is not thoroughly enforced. According to PC magazine, ${ }^{12}$ "shareware is software sold on the honor system." Paying for shareware will upgrade one's status to "registered user" but will do little else except show support and appreciation to the software developer. The process of registration usually consists of inputting a combination of a license holder name and a serial key into the software. That information is usually e-mailed after the registration process is completed. That process and the associated payment are usually initiated from within the shareware or from the developer's website.

Finally, software distributed through "trialware" (or "demoware") is software for which payment is both expected and enforced. In this third digital software distribution model, a trial version of the software product is made available, allowing users to try the product before they decide whether to purchase a license or not. Contrary to other digital software distribution models, the demo or trial version is only accessible during a pre-determined evaluation period. This period is often defined by time (eg, 30 days), by a number of allowed free uses or by a combination of both. Upon reaching the end of the evaluation period, the software product can no longer be accessed unless the user acquires a license. After completing the license purchasing process, software publishers may: (1) send a serial key by email to license holders, (2) e-mail customers a link where they can download the unlocked installation package or (3) use a software activation solution to effectively unlock the trial version. In the context of digital software delivery, activation solutions are often referred to as electronic software distribution (ESD) solutions. As was the case for software activations in the physical distribution channel, ESD solutions also use a client-server activation process and are therefore DRM solutions in nature.

\section{Transaction cost analysis}

TCA, sometimes referred to as transaction cost economics or theory, finds its origin in the
Ronald Coase ${ }^{13}$ essay The nature of the firm, in which the author attempts to explain why firms exist - why they are created in the first place. Much of the modern literature on TCA, however, stems from Williamson's book Markets and Hierarchies, ${ }^{14}$ and his subsequent work on the subject, which resurrected the research topic and provided most of the foundations of what can now be called a theory.

At its core, "TCA explicitly views the firm as a governance structure" 15 (p. 31) where the firm is not the only governance option available. According to TCA, the choice of structure to use when conducting an economic activity should be based on careful analysis of the context in which the transaction will evolve and, in its simplest form, decision makers are to choose between market-type organizations or hierarchical organizations. For example, a firm needing a specific component for the final assembly of one of its products should investigate whether to purchase that component from a supplier (known as a market-type governance structure) or to build the capacity in-house and produce the component on its own (called a hierarchical structure). While trying to add a level of nuance to these initial theoretical underpinnings, Joskow ${ }^{16}$ introduced a third governance structure option: long-term contracts. This new option was positioned in between spot market orders and in-house production and was introduced to reflect popular recourse to the long-term supplierclient relationships that are prevalent in the marketplace. Although the classic governance duality has since evolved into a continuum between the two traditional opposites, the basic principle of TCA remains: decision makers should consider different governance structure options and choose the one that will incur the least total costs.

The following paragraphs detail the main theoretical foundations tied to TCA, namely the theory assumptions, the transaction dimensions and the transaction costs. They also highlight the main studies in the field of e-commerce that relied on TCA as one of their theoretical backgrounds.

\section{Assumptions}

According to TCA, three assumptions must be present in order for the tenet to hold: bounded 
rationality, opportunism and risk neutrality. Bounded rationality states that any decision maker, or "contractual man" as Williamson ${ }^{17}$ (p. 43) calls him, has limited and finite analytical skills. This means that no decision maker could ever produce a decision tree that would map recourse for every possible change in the environment of an exchange between trading partners. Opportunism is the assumption that allows for trading agents to individually seek to benefit from any relative advantages they may hold. In other words, trading partners may opt to pursue their own personal interests rather than the common interests of all members of an exchange, a reality decision makers must address when considering different governance options. Finally, risk neutrality implies that decision makers attribute a level of risk to alternative governance options, but only use expected outcome as the metric that will guide their decisions. In other words, a decision maker will have no preference towards a high risk or a low risk alternative as long as they both produce the same expected return (in economic terms).

\section{Transaction dimensions}

According to Williamson, "a transaction occurs when a good or service is transferred across a technologically separable interface. One stage of activity terminates and another begins" 18 (p. 552). In TCA, the transaction under study represents the unit of analysis, and the context in which it will take place will define what governance option should be implemented. Four dimensions define the context in which the transaction will evolve: frequency, asset specificity, behavioral uncertainty and environmental uncertainty. Williamson defines the frequency dimension as "the volume of transactions processed through a given arrangement" ${ }^{19}$ (p. 60). And, according to the author, "higher levels of transaction frequency provide an incentive for firms to employ hierarchical governance structures, because 'the cost of specialized governance structures will be easier to recover for large transactions of a recurrent kind",20 (p. 60). Williamson defines specific assets as "durable investments that are undertaken in support of particular transactions, the opportunity cost of which investments is much lower in best alternative uses or by alternative users should the original transaction be prematurely terminated" 21 To counter the risk of opportunism in market governance, transactions that are supported by higher specific assets incur higher contracting, monitoring and enforcement costs. ${ }^{22}$ Therefore, as asset specificity increases, so does the propensity to adopt a hierarchical governance structure (p. 55). Behavioral uncertainty represents uncertainty as it relates to the actions of trading partners. On the subject, Williamson wrote, "Uncertainty of a strategic kind is attributable to opportunism and will be referred as behavioral uncertainty" 23 (p. 59). John and Weitz focus more on "the difficulty of ascertaining the actual performance or adherence to contractual agreements" 24 (p. 342) when defining this dimension. In all cases, as behavioral uncertainty increases, so does the propensity to adopt hierarchical governance structures, the type of structure that provides the best protection against opportunism.

Noordeweier et al. define environmental uncertainty as "Unanticipated changes in circumstances surrounding an exchange" 25 (p. 82). In contrast to the behavioral kind, environmental uncertainty is not strategic in nature and does not find its source in the opportunism assumption. Rather, it finds its source in the bounded rationality assumption. ${ }^{26}$ The fact that decision makers do not have the processing capacity to map a decision tree that would dictate the correct course of action for every possible contingency is what allows environmental uncertainty to exist. In theory, as environmental uncertainty increases, so do the costs of drafting the precise contracts required in bilateral market-type governance structures. Therefore, as environmental uncertainty increases, so does the propensity to adopt hierarchical governance structures (all other things being equal).

\section{Transaction costs}

Whereas most of the TCA literature has focused on identifying the transaction dimensions that influence the governance structure chosen, "a small but growing number of TCA researchers have attempted to measure transaction costs directly"27 (p. 43). Indeed, while the alignment of transaction dimensions provides guidance in choosing the correct governance structure, the implied impact they have on 
transaction costs represents the core of the theory's argument. By simultaneously measuring transaction costs and transaction dimensions, researchers can potentially test the entire TCA model, rather than only the link between transaction dimensions and governance decisions.

Pilling et al. ${ }^{28}$ adopted this thorough research approach by measuring both transaction dimensions (asset specificity, external uncertainty and frequency) and transaction costs (effort to develop and maintain a relationship, monitoring and guarding against opportunism). Their findings partly support the theory that transaction costs are found to be influenced by dimensions and that those costs influence the dimensions of relationalism between two firms. Walker and Poppo ${ }^{29}$ used a similar approach in measuring both dimensions and transaction costs. In their case, the dimension measured was asset specificity, and the transaction costs were engineering change cost allocation and material cost allocation. Their findings showed that asset specificity generated lower transaction costs when governance was handled within the organization.

As can be noted from the preceding brief literature review, researchers in the field rarely assess the same transaction costs. Rather, they tend to explore measurable transaction costs that apply to the context of their research. Nevertheless, in their broad review, Rindfleish and Heide $^{30}$ (p. 46) produced a chart detailing the most common forms of transaction costs across the TCA literature. These are, costs of crafting safeguards; communication, negotiation and coordination costs, screening and selection costs and measuring costs.

\section{Literature review of TCA in e-commerce research}

While originally developed by economic scholars, TCA is a vibrant research stream that has been studied by numerous researchers in several disciplines including economics, sociology, political science, organization theory, contract law, corporate finance, marketing and information systems. Several researchers ${ }^{31-33}$ have also published literature reviews of TCA and its applications.

Closer to our subject matter, TCA has also been applied to e-commerce research. Within this particular research stream, some authors have attempted to measure both transaction dimensions and transaction costs. For example, Liang and Huang ${ }^{34}$ tested whether consumers would buy products from the channel (offline versus online) that produced the lowest transaction costs, which would predict TCA. Dimensions of asset specificity and uncertainty were measured, as well as costs stemming from the following activities: search, comparison, examination, negotiation, payment, delivery and post-service. Their results showed that certain categories of products were seen by consumers as better adapted to the online channel because they produced lower levels of transaction costs. Their findings also showed that relatively higher perceived transaction costs did lead to lower e-commerce acceptance by consumers.

In their study, Devaraj et al. ${ }^{35}$ hypothesized that channel preference would be influenced by channel satisfaction. The authors set out to explore whether technology acceptance, transaction costs and service quality were antecedents to channel satisfaction. Specifically, they assessed two transaction dimensions, namely asset specificity and uncertainty, and three transaction costs, namely time, ease and price savings. Their findings showed that asset specificity and uncertainty did influence transaction costs and that those costs did affect channel satisfaction, which ultimately influenced channel preference.

Finally, Teo and $\mathrm{Yu}^{36}$ explored whether key dimensions of TCA, when mediated by transaction costs, could explain consumers' willingness to buy online. Uncertainty and frequency were the dimensions studied, while searching costs, monitoring costs and adapting costs were the transaction costs assessed. Their findings showed that transaction costs were negatively associated with consumers' willingness to buy online, as predicted by the theory.

\section{RESEARCH MODEL AND HYPOTHESES}

The research model (Figure 1) operates in two different contexts (ie, transactions): the first transaction will be referred to as license acquisition and the second as license management. We define the license acquisition transaction as the container for every process required between the moment a potential customer decides to purchase a software license 


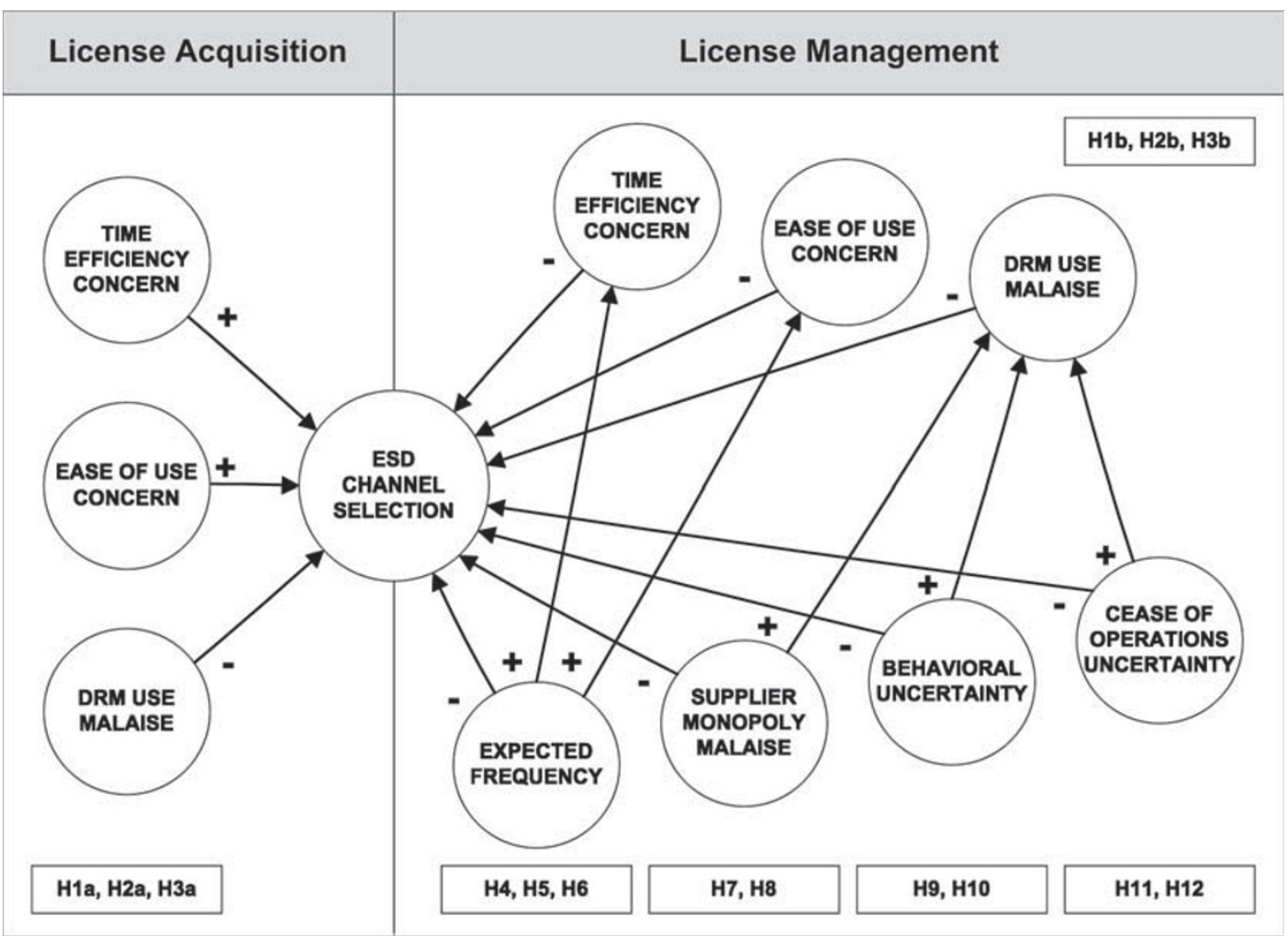

Figure 1: Research model

and the moment he first gains full access to the product. A representation detailing this transaction is provided in Figure 2. We define the license management transaction as the container for every process required between the moment a software license holder decides to "move" his license and the moment he regains full access to the reinstalled software. Moving a license occurs, for example, when license holders need to regain access to a software product following a computer upgrade or any type of computer failure. A representation detailing this transaction is provided in Figure 3.

Furthermore, the research model comprises the following 11 variables: the dependent variable: (1) distribution channel choice; three transaction costs tied to the license acquisition transaction, (2) time efficiency concern, (3) ease of use concern and (4) DRM use malaise; and the same three transaction costs $(5,6,7)$ along with four transaction dimensions tied to the license management transaction, namely: (8) expected frequency, (9) supplier monopoly malaise, (10) behavioral uncertainty and (11) cease of operations uncertainty.
This section provides a definition for each of the research variables, details the hypotheses concerning the relationships between these variables and introduces the control variables that may influence the distribution channel choice.

\section{DEFINITION OF THE RESEARCH VARIABLES}

\section{Dependent variable}

In the TCA framework, the traditional governance options, namely markets and hierarchies, differ according to the extent to which the transactional processes are internalized or externalized. Indeed, the hierarchy governance option effectively internalizes all key processes in-house, whereas the market governance option externalizes important processes to outside vendors. The same distinction exists between the transaction processes supporting the physical delivery and the electronic delivery of software products. Customers requesting physical delivery of a CDROM during the license acquisition transaction 


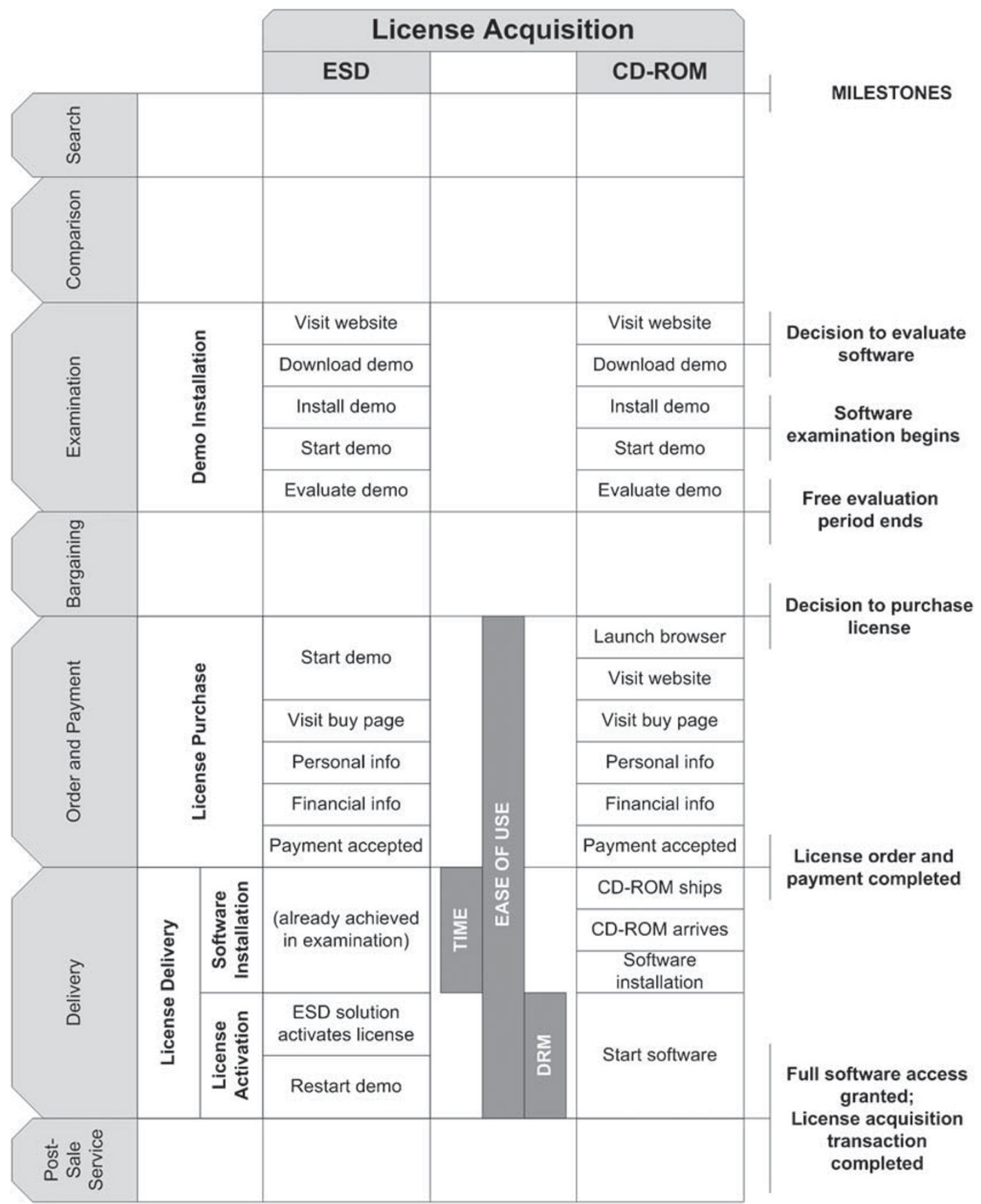

Figure 2: Portrayal of the license acquisition transaction

are in effect choosing to internalize future license-management transactions, an option which will allow them to become independent of software vendors when reinstalling the software. In contrast, consumers choosing the ESD channel option during the license acquisition transaction are effectively externalizing the license delivery processes to the DRM system provider (ie, software publisher). In turn, they will need to connect to the DRM systems in order to regain access to the software product whenever a 


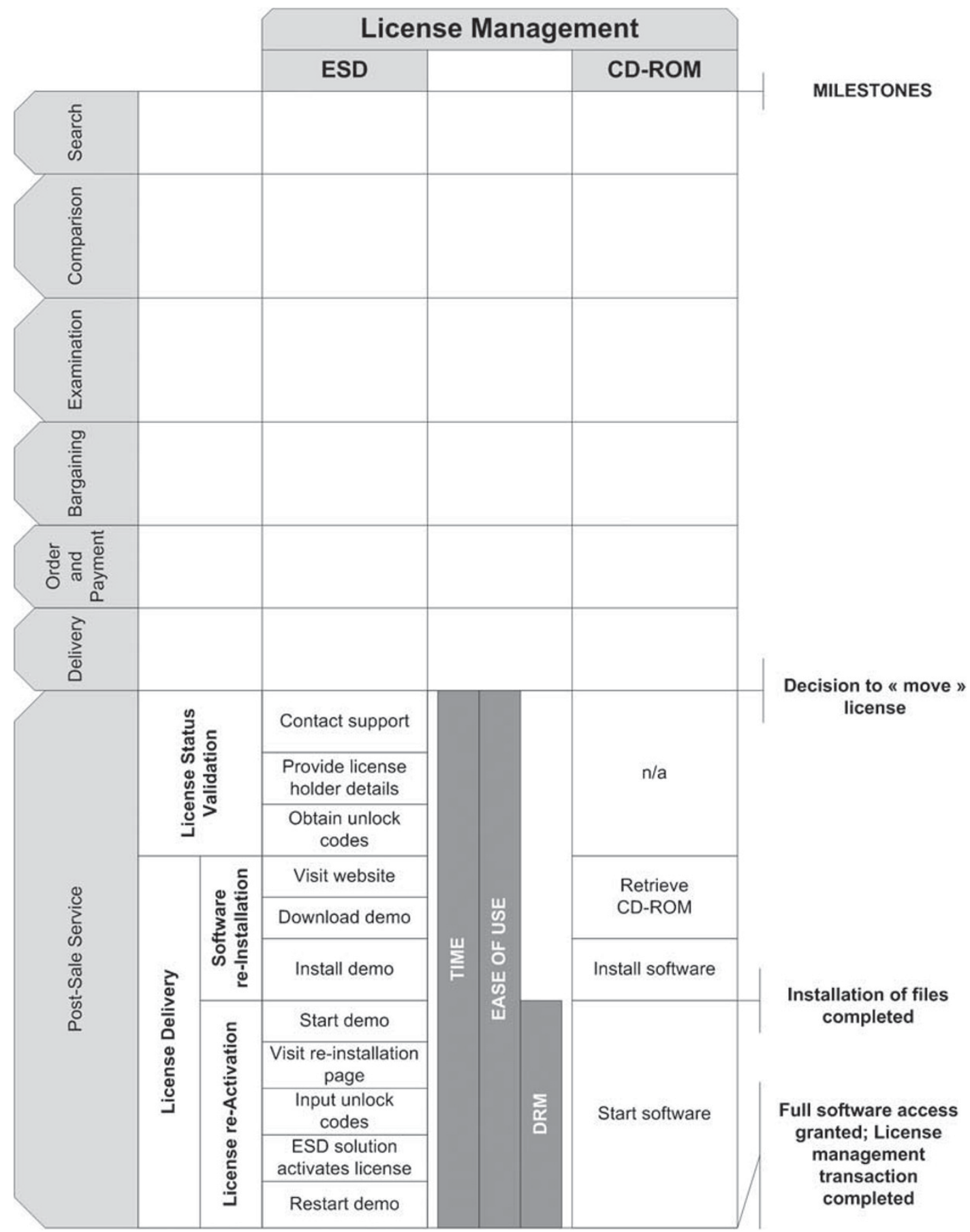

Figure 3: Portrayal of the license management transaction

license management transaction is be requested.

As such, this research views the physical distribution channel alternative not tied to any DRM technologies (ie, CD-ROM) as being equivalent to the traditional hierarchy governance option, and the digital distribution channel alternative channel that uses DRM technologies (ie, ESD through demo-unlock) as being equivalent to the market governance option. 


\section{Transaction costs}

Time efficiency concern is defined as the level of importance a customer places on tasks being conducted in the least possible time. Ease of use concern is defined as the level of importance a customer places on tasks being conducted with the least possible difficulty. Both were adapted from Devaraj et al. ${ }^{37}$ Finally, DRM-use malaise is defined as a customer's level of discomfort with using a DRM system in order to access digital content. This third construct was created and included in the research model following Fetscherin's ${ }^{38}$ findings, which demonstrated that consumers were uncomfortable when accessing digital content protected by DRM systems.

\section{Transaction dimensions}

The TCA framework only applies to transactions that are recurrent. ${ }^{39}$ Within the context of our research, the license acquisition transaction is not considered recurrent because consumers purchase a license only once for a given software product. On the other hand, the license management transaction is considered recurrent because license holders will presumably need to reinstall their license at least a few times during the lifecycle of their use of a software product. This explains why the four transaction dimensions included in the research model only apply to the license management transaction.

The following argument further justifies our decision not to apply transaction dimensions to the license acquisition context. If a potential customer rates behavioral uncertainty as especially high for the license acquisition transaction, it could mean that this person views the risk associated with paying and not receiving the product as high. In such cases, the potential customer would likely choose not to purchase the product entirely and would not be making a distribution channel decision as a result.

The four transaction dimensions are defined as follows. Expected frequency is defined as a customer's expected volume for a given transaction, in our case for the license management transaction. It was adapted from Pilling et al. ${ }^{40}$

Supplier monopoly malaise is the proxy used to measure the asset specificity construct. This variable was adapted from the supplier market competition construct used by Walker and Weber ${ }^{41}$ It is defined as a customer's perceived level of discomfort caused by the fact that a product is available or sold by one single supplier. When using the ESD channel, customers are placed in a position where asset specificity is undeniably high, since the DRM system is a specific, intangible asset of the dedicated kind that has no other use than to manage software licenses. Customers who choose the ESD channel have no other alternative than to use the DRM system whenever a license management transaction is required.

Behavioral uncertainty is defined as a customer's perceived belief that a supplier would strategically lie or hide relevant "terms and conditions" information. Contrary to a typical supplier-client relationship, however, where a client would be faced with a performance evaluation problem, ${ }^{42}$ software license holders can instantly recognize the level of performance they are getting. For example, license holders requesting reactivation to software after its re-installation will know if this request has been granted by the software vendor or if new fees are imposed.

Finally, Cease of operations uncertainty is defined as a customer's perceived belief that a supplier will cease its business operations while an exchange relationship is ongoing. The decision to use a specific proxy is based on the lack of empirical evidence of a link between environmental uncertainty at large and vertical integration in the literature, as reported by Rindfleisch et al. ${ }^{43}$ and Krickx. ${ }^{44}$ And, as Robertson and Gatignon ${ }^{45}$ conclude, environmental uncertainty is probably multidimensional. Consequently, we propose to measure environmental uncertainty through this new specific dimension. The outcome resulting from a supplier ceasing to operate its business operations is consistent with the definition of the construct, in that it is believed to be both unanticipated and a valid circumstance surrounding an exchange.

\section{HYPOTHESES}

\section{Time efficiency concern}

Becker ${ }^{46}$ argued that consumers maximise their utility based on time constraints. Devaraj et al. ${ }^{47}$ used this argument to empirically demonstrate that increased satisfaction with the electronic commerce channel was influenced by gains in time efficiency. In the particular case of this study, customers most concerned about their 
time will likely choose the delivery option that is most time efficient. Thus, between the two available options, customers most concerned about using the product as rapidly as possible are likely to select the ESD channel, since this option grants customers instantaneous full access to the software product following a license purchase. The distribution of a CD-ROM requires significantly more time because the medium must be physically shipped to customers before they can start using it. If, however, customers decide to reinstall their software, the ESD option should be more time-consuming, since customers would have to reconnect to the DRM system, input their manual unlock codes and possibly contact the publisher's tech support if they misplaced those codes before they could regain access to the software. By using the other software delivery alternative, license holders would simply need to reinstall the software product from the CD-ROM in order to regain access to it (see Figure 2). These arguments lead to the first two hypotheses:

H1a: For the license acquisition transaction, time efficiency concern increases the likelihood that ESD will be the selected distribution channel.

$H 1 b$ : For the license management transaction, time efficiency concern decreases the likelihood that ESD will be the selected distribution channel.

\section{Ease of use concern}

Devaraj et al. ${ }^{48}$ demonstrated that customers would see their satisfaction for the e-commerce channel augmented if they found it to be easy to use. In the particular case of this study, customers most concerned about how easy it is to purchase a software product sold through a trialware marketing strategy are likely to choose the ESD option because the ordering process takes place from within the demo version, which eliminates the need to start up a web browsing application, visit the publisher's website and order from there. As for the license management transaction, the physical delivery option should be the easiest because it only requires the license owner to re-install the software product from the CD-ROM, unlike the ESD option, which requires customers to download the installation files from the software vendor's website before proceeding with the installation. Based on these arguments, we posit that

H2a: For the license acquisition transaction, ease of use concern increases the likelihood that ESD will be the selected distribution channel.

$H 2 b$ : For the license management transaction, ease of use concern decreases the likelihood that ESD will be the selected distribution channel.

\section{DRM use malaise}

In his research on consumers' acceptance of the various technological requirements and the types of usage restrictions that DRM systems impose when accessing content in the form of movie downloads, Fetscherin ${ }^{49}$ found that consumers most objected to DRM systems that required the use of specific encryption, software or hardware components. Since software products delivered by way of ESD require the use of a DRM system (which in effect is a mandatory software component), it is likely that customers will feel as uncomfortable as when accessing movie downloads that require a specific software component.

A similar argument can be made for license management transactions. Since license holders who use the ESD channel need to connect to the DRM system to reactivate their license, it is likely they will feel a similar malaise. This last argument extends from Fetscherin's ${ }^{50}$ findings, which have demonstrated that consumers most objected when DRM systems placed restrictions on the playability of digital content. As a result, we propose the next two hypotheses:

H3a: For the license acquisition transaction, DRM-use malaise decreases the likelihood that ESD will be the selected distribution channel.

$H 3 b$ : For the license management transaction, DRM-use malaise decreases the likelihood that ESD will be the selected distribution channel. 


\section{Expected frequency}

The relationship between the frequency dimension and the dependent variable of governance structure is often discussed in the TCA literature, but researchers have found the link between these two variables to be generally insignificant when tested empirically. ${ }^{51}$ In spite of past research findings, we maintain that the dimension of frequency could presumably influence the software distribution channel choice. Indeed, customers expecting numerous software reinstallations will want to shield themselves from potentially opportunistic software vendors by internalizing crucial processes, in this case by using the CD-ROM channel option. Therefore,

H4: For the license management transaction, expected frequency decreases the likelihood that ESD will be the selected distribution channel.

Furthermore, the frequency dimension should also have an impact on transaction costs, as customers expecting to frequently reinstall the software should have greater concern for both time efficiency and ease of use than customers who do not. Consequently,

H5: For the license management transaction, expected frequency is positively related to time efficiency concern.

H6: For the license management transaction, expected frequency is positively related to ease of use concern.

\section{Supplier monopoly malaise}

Numerous authors ${ }^{52-54}$ have demonstrated that the propensity to adopt a hierarchical structure of governance increases as asset specificity rises. In their study on the procurement of "simple components in a manufacturing division of a large US automobile company," Walker and Weber $^{55}$ used the level of supplier-market competition as a proxy for the construct of asset specificity, arguing that "high supplier competition decreases the potential for opportunistic bargaining" 56 (p. 376). Their empirical results demonstrate that higher levels of supplier market competition increase the likelihood that a buy decision would be made, as opposed to a make decision. Based on their findings, it is thus more likely that customers who view the lack of supplier competition as problematic (via supplier monopoly malaise) will likely employ a hierarchical structure instead of a market governance structure. Adopting such a structure will shield them from the possibility of opportunistic behavior by the monopolistic supplier, a risk even more present if this supplier is aware of its advantageous position. As a result, we propose that

H7: For the license management transaction, supplier monopoly malaise decreases the likelihood that ESD will be the selected distribution channel.

Additionally, Bradbury reports a discussion held with Edward W. Felten of Princeton University during which the professor argued that, "any DRM you design will have someone in charge of deciding who is in charge of operation and who isn't. Once you do that, you know that whoever has the control will use it for their own business purposes" ${ }^{\prime 7}$ (p. 32). Essentially, Felten is pointing out that users of DRMmanaged content have no other choice but to yield access control to those who operate the DRM systems. As a result, in the particular case of this study, customers who are uncomfortable dealing with a monopolistic supplier should also experience feelings of malaise resulting from using a DRM system they do not control. We hypothesize that

H8: For the license management transaction, supplier monopoly malaise is positively related to DRM-use malaise.

\section{Behavioral uncertainty}

Anderson and Schmittlein ${ }^{58}$ have demonstrated that in seeking protection against opportunism, decision makers would tend to adopt hierarchical governance structures when behavioral uncertainty was high. These authors measured behavioral uncertainty through the 
difficulty of evaluating performance. Their findings showed that the use of direct salesperson employees (ie, a hierarchy structure), as opposed to manufacturers' representatives (ie, a market structure), was associated with the increasing difficulty of evaluating performance (ie, behavioral uncertainty). In the context of our study, license holders who find it likely that software publishers would try to gain from strategic uncertainty regarding license management transactions will likely want to shield themselves by choosing to manage its processes internally. Consequently, we hypothesize that

H9: For the license management transaction, behavioral uncertainty decreases the likelihood that ESD will be the selected distribution channel.

Furthermore, behavioral uncertainty should also impact the transaction cost of DRM-use malaise. Indeed, customers should be uncomfortable with yielding control of their license management transactions over to a DRM system if they fear that terms and conditions might not be respected in the future.

H10: For the license management transaction, behavioral uncertainty is positively related to DRM-use malaise.

\section{Cease of operations uncertainty} John and Weitz ${ }^{59}$ have demonstrated that manufacturers rely more on direct channels as environmental uncertainty increases. Similarly, customers who have little confidence in the software vendor's ability to conduct its business operations will likely want to internalize their license management processes. Therefore,

H11: For the license management transaction, cease of operations uncertainty decreases the likelihood that ESD will be the selected distribution channel.

Additionally, license holders might be uncomfortable with yielding control of their license management transactions to a DRM system if they foresaw a situation where the DRM provider would no longer be able to grant software activation requests. Thus,

\section{H12: For the license management transaction, cease of operations uncertainty is positively related to DRM-use malaise.}

\section{Control variables}

While absent from the representation of the research model, two factors were retained as control variables because they could potentially affect channel choice decisions: internet connection speed and prior channel experience.

\section{Internet connection speed}

The speed of the internet connection on the computer from which a license purchase is made could potentially affect the choice of channel used. Indeed, users with very slow internet connections may not find it worthwhile to download a demo version of significant size before ordering, as required by ESD transactions. In such cases, they would likely order a CDROM from the website.

\section{Prior channel experience}

Consumers' prior experience with ESD could potentially affect their choice of software distribution channel. Indeed, the fact that ESD is a relatively new copy protection solution could influence consumers with no prior experience in ESD to choose the physical distribution channel (ie, CD-ROM) to purchase the software license.

\section{RESEARCH METHOD}

\section{Data collection strategy}

The study sample will include customers that have already tested a demo version of one of the products of a fitness software publisher and are now ready to purchase. This sample will only include customers who are purchasing a license intended for their own use on the computer where the software product will be installed and used. Indeed, software licenses that are intended to be given as gifts and/or installed and used on another computer will not be considered in this 


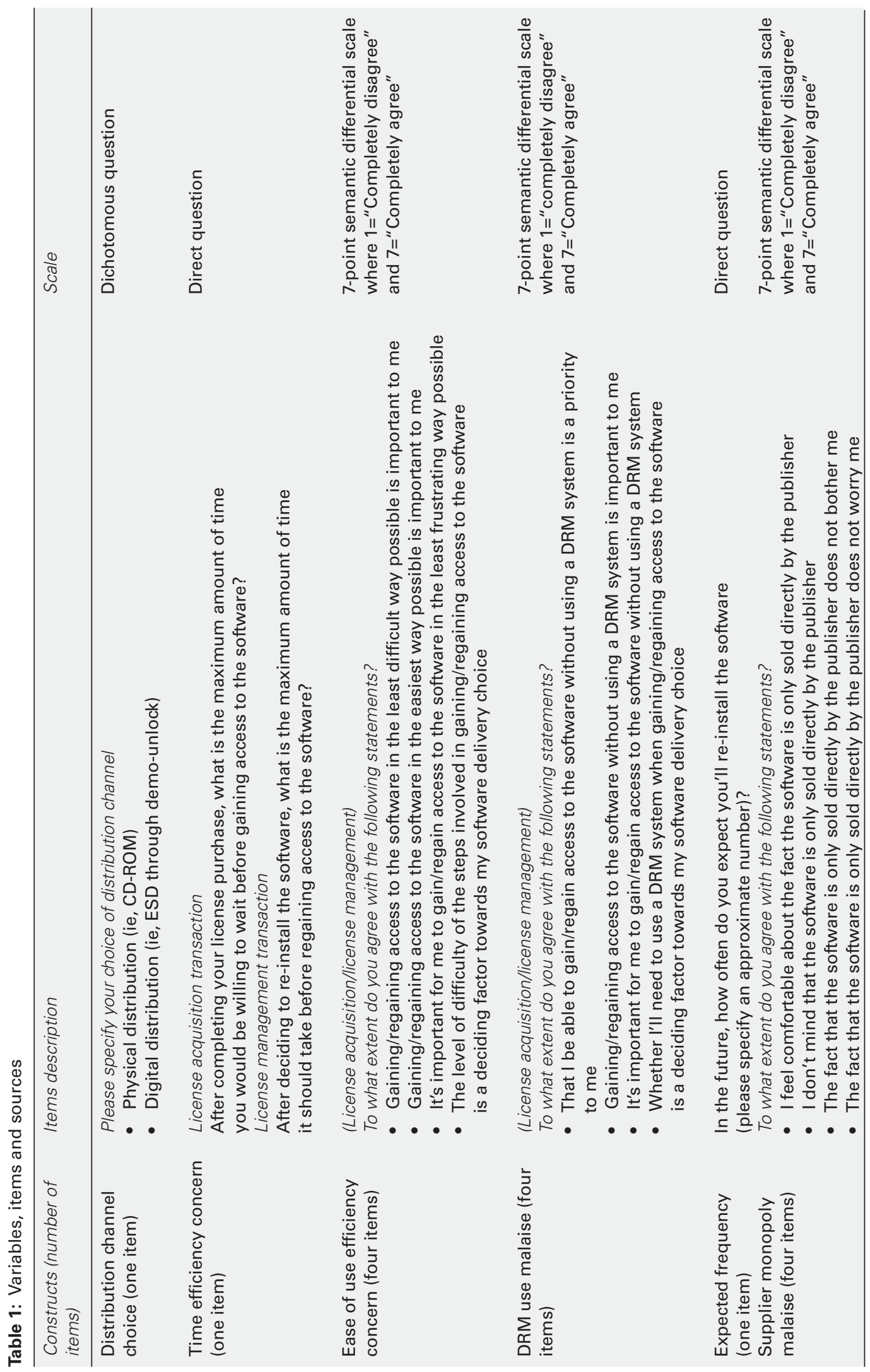




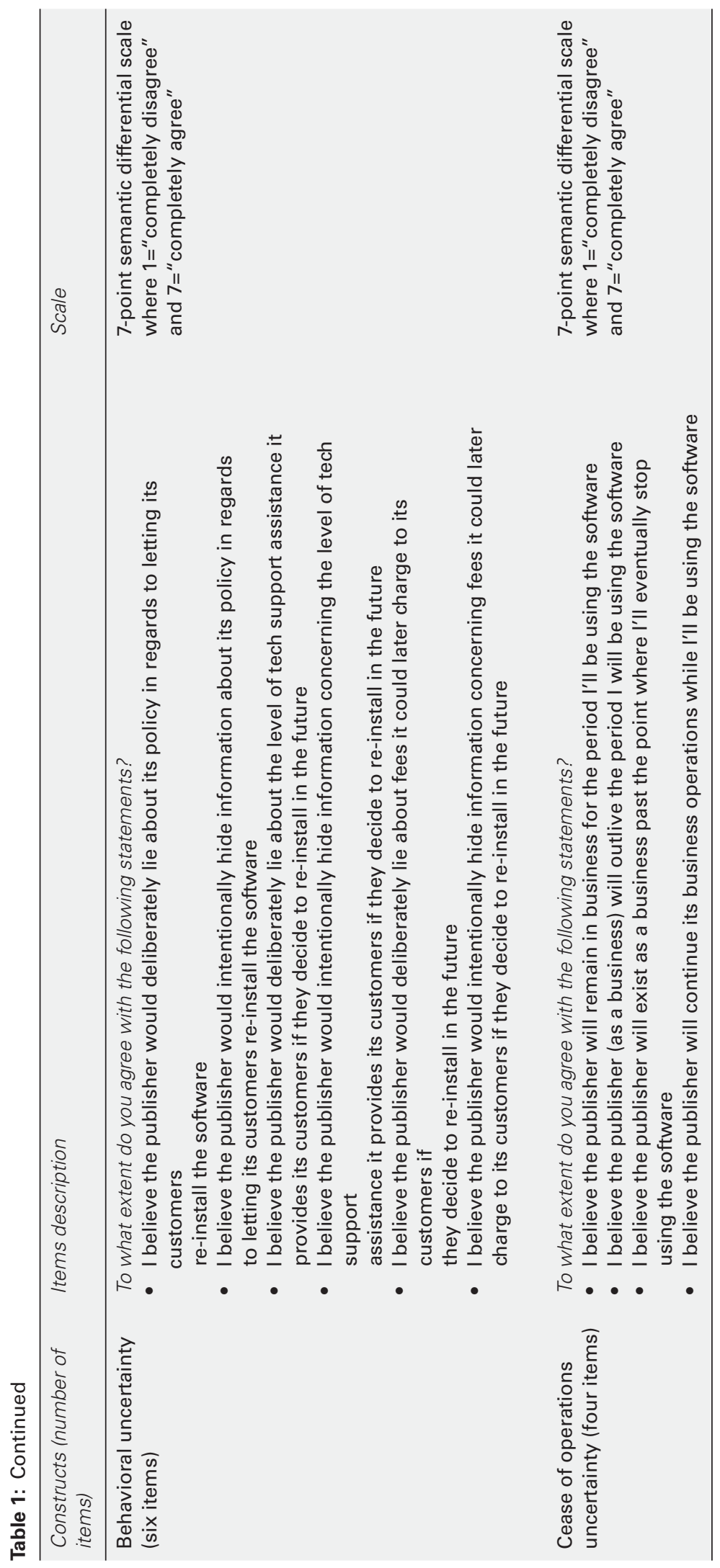


study, as they generally favor the purchase of a CD-ROM. To limit channel-choice bias, the study sample will also allow for product prices to be controlled. As such, the cost of shipping a CD-ROM to consumers will be waived by the software publisher for the duration of the data collection procedure. Finally, the study sample will comprise only customers residing in Canada and the USA because electronic software delivery is the only channel option offered by the software publisher to consumers residing in other countries.

All data will be collected using an electronic questionnaire. Even though an electronic survey is likely to provide a relatively lower response rate than the traditional mail questionnaire, it offers considerable advantages compared to the latter, as it reduces costs and response cycle time $^{60}$ while eliminating data re-entry errors. ${ }^{61}$ When starting the license acquisition process (via hyperlinks on their computer desktops or from the publisher's website), consumers will be directed to a web page describing the research project. Their optional participation will be made possible by following a hyperlink to the electronic survey.

\section{Research variables}

The development of the instrument was carried out in three stages. During the first stage item creation - pools of items for each construct were created by identifying items from existing scales, and by creating additional items, which appeared to fit the construct definitions. ${ }^{62}$ During the second stage - scale development - two panels of judges sorted the items from the first stage into separate categories based on the similarities and differences among items (ie, card-sorting procedure). Based on their placement, the items could then be examined and any inappropriately worded or ambiguous items could be eliminated. ${ }^{63}$ Finally, during the instrument testing stage, two pilot tests were conducted to assure the validity of the survey instrument. ${ }^{64}$ The first pilot test lasted for a period of three weeks and produced 37 completed questionnaires. Because of the limited sample size, a CFA at a mono-method level of analysis was conducted to assess unidimensionality, convergent validity and internal consistency for each construct of the research model. ${ }^{65}$ Internal consistency was further assessed by computing the Cronbach's alpha. ${ }^{66}$ Because the constructs did not score perfectly on all unidimensionality, convergent validity and internal consistency indicators, modifying the troublesome items was deemed necessary. Following these, a second pilot test was performed. It produced 36 completed questionnaires and its results indicated sufficient support for all previously used indicators as well as the discriminant validity. Table 1 presents the final operationalization of the research variables.

\section{Analytical procedures}

Since the dependent variable of the research model is a 0.1 dummy variable, the logit model will be used to assess the extent to which the 10 independent variables explain the variance (Pseudo $R^{2}$ ) of the distribution channel choice. ${ }^{67}$ To test the research hypotheses tied to the relationships between the transaction costs and the dependent variable, however, another two logistic regressions will be required: one for the license acquisition transaction and another for the license management transaction. Finally, three ordinary least squares will be calculated to test the research hypotheses tied to the relationships between the transaction dimensions and the transaction costs in the license management transaction.

\section{CONCLUSION}

This study should make five notable theoretical contributions. First, it is the first to address ESD by pitting it against another distribution channel. Secondly, this research proposes a novel application of TCA to the software industry, specifically to the distribution of software products when licenses are acquired online. This study hints that TCA can arguably be applied to any context that can be framed in contracting terms, as predicted by Williamson. ${ }^{68}$ Thirdly, this study suggests that TCA researchers could benefit from addressing the complete lifecycle of a relationship by closely studying its subtransactions. This procedure should prove particularly relevant for relationships in which different transactions would dictate different governance choices. Potentially, this could lead researchers to accurately pinpoint which specific transactions are relevant to decision makers and which are not. Fourthly, following the lead of previous studies, this research proposes to assess 
both the transaction dimensions and transaction costs included in the TCA framework. Finally, this study introduces new proxies for measuring asset specificity and environmental uncertainty, namely supplier monopoly malaise and cease of operations uncertainty. These could be used in other studies since their operationalization was tested to confirm unidimensionality, validity and reliability.

This research should also have two main implications for managers. It should help software managers better understand why their customers prefer one distribution channel to another, and should provide publishers with relevant information that should help them steer their customer base towards using the most profitable delivery channel. Also, by validating the proposed relationship between the cease of operations uncertainty dimension and the distribution channel choice, the findings should confirm the importance for software publishers of promoting strong financial foundations when engaging with potential customers.

\section{References and Notes}

1 According to BSA and IDC, the worldwide software piracy rate is at 35 per cent, which means that "for every two dollars' worth of PC software purchased legally, one dollar's worth was obtained illegally" (quote BSA IDC, p. 1).

2 Association of American Publishers inc. (2001) 'Digital rights management for ebooks: publishers requirements version 1.0. [e-book]', (Cited 23 July 2007). Available from. http://publishers.org/digital/ drm.pdf.

3 Bradbury, D. (2007) 'Decoding digital rights management', Computers and Security, Vol. 26, pp. 31-33.

4 Fetscherin, M. (2006) 'Digital rights management: What the consumer wants', Journal of Digital Asset Management, Vol. 2, No. 3, pp. 143-149.

5 Williamson, O. E. (1985) The Economic Institutions of Capitalism: Firms, Markets, Relational Contracting. Free Press, New York.

6 Rindfleisch, A. and Heide, J. B. (1997) 'Transaction cost analysis: Past, present, and future applications', Journal of Marketing, Vol. 61, No. 4, pp. 30-54.

7 Moores, T. and Dhillon, G. (2000) 'Software piracy: A view from Hong Kong', Communications of the $A C$, Vol. 43, No. 12, pp. 88-93.

8 Conner, K. R. and Rumelt, R. P. (1991) 'Software piracy: An analysis of protection strategies', Management Science, Vol. 37, No. 2, pp. 125-139.
9 Altinkemer, K. and Guan, J. (2003) 'Analyzing protection strategies for online software distribution', Journal of Electronic Commerce Research, Vol. 4, No. 1, pp. 34-48.

10 Sundararajan, A. (2004) 'Managing digital piracy: Pricing and protection. Information', Systems Research, Vol. 15, No. 3, pp. 297-308.

11 Gopal, R. D. and Sanders, G. L. (1997) 'Preventive and deterrent controls for software piracy', Journal of Management Information Systems, Vol. 13, No. 4, pp. 29-47.

12 PC MAG Encyclopedia. (2007) (homepage on the Internet). (cited 9 July 2007). Available from:. http:// www.pcmag.com/encyclopedia_term/ $0,2542, \mathrm{t}=$ shareware $\& \mathrm{i}=51251,00$.asp.

13 Coase, R. H. (1937) 'The nature of the firm', Economica N. S., Vol. 4, pp. 386-405.

14 Williamson, O. E. (1975) Markets and Hierarchies: Analysis and Antitrust Implications. Free Press, New York.

15 See ref 6 above.

16 Joskow, P. L. (1988) 'Asset specificity and the structure of vertical relationships: Empirical evidence', Journal of Law, Economics, and Organization, Vol. 4, No. 1, pp. 95-117.

17 See ref 5 above.

18 Williamson, O. E. (1981) 'The economics of organization: The transaction cost approach', The American Journal of Sociology, Vol. 87, No. 3, pp. $548-577$.

19 See ref 5 above.

20 ibid.

21 ibid.

22 See ref 6 above.

23 ibid.

24 John, G. and Weitz, B.A. (1988) 'Forward integration into distribution: An empirical test of transaction costs analysis', Journal of Law, Economics, and Organization, Vol. 4, No. 2, pp. 337-355.

25 Noordewier, T. G., John, G. and Nevin, J. R. (1990) 'Performance outcomes of purchasing arrangements in industrial buyer-vendor relationships', Journal of Marketing, Vol. 54, No. 4, pp. 80-93.

26 See ref 6 above.

27 ibid.

28 Pilling, B. K., Crosby, L. A. and Jackson Jr., D. W. (1994) 'Relational bonds in industrial exchange: An experiment test of the transaction cost economic framework', Journal of Business Research, Vol. 30, pp. 237-251.

29 Walker, G. and Poppo, L. (1991) 'Profit centers, single-source suppliers, and transaction costs', Administrative Science Quarterly, Vol. 36, No. 1, pp. 66-87.

30 See ref 6 above.

31 See ref 16 above. 
32 Shelanski, H. A. and Klein, P. G. (1995) 'Empirical research in transaction cost economics: A review and assessment', The Journal Law, Economics, and Organization, Vol. 11, No. 2, pp. 335-361.

33 See ref 6 above.

34 Liang, T. and Huang, J. (1998) 'An empirical study on consumer acceptance of products in electronic markets: A transaction cost model', Decision Support Systems, Vol. 24, No. 1, pp. 29-43.

35 Devaraj, S., Fan, M. and Kohli, R. (2002) 'Antecedents of b2C channel satisfaction and preference:Validation e-Commerce metrics', Information Systems Research, Vol. 13, No. 3, pp. 316-333.

36 Teo, T. S. H. and Yu, Y. (2005) 'Online buying behavior: A transaction cost economics perspective', Omega, Vol. 33, No. 5, pp. 451-465.

37 See ref 34 above.

38 See ref 4 above.

39 See ref 5 above.

40 See ref 27 above.

41 Walker, G. and Weber, D. (1984) 'A transaction cost approach to make-or-buy decisions', Administrative Science Quarterly, Vol. 29, No. 3, pp. 373-391.

42 Anderson, E. and Schmittlein, D. C. (1984) 'Integration of the sales force: An empirical examination', The Rand Journal of Economics, Vol. 15, No. 3, pp. 385-395.

43 See ref 6 above.

44 Krickx, G. A. (2000) 'The relationship between uncertainty and vertical integration', The International Journal of Organizational Analysis, Vol. 8, No. 3, pp. 309-329.

45 Robertson,T.S. and Gatignon,H. (1998) ‘Technology development mode: A transaction cost conceptualization', Strategic Management Journal, Vol. 19, No. 6, pp. 515-531.

46 Becker, G. S. (1965) 'A theory of the allocation of time', Economic Journal, Vol. 75, pp. 493-517.

47 See ref 34 above.
48 ibid.

49 See ref 4 above.

50 ibid.

51 See ref 6 above.

52 See ref 41 above.

53 See ref 23 above.

54 Klein, S., Frazier, G. L. and Roth, V. J. (1990) 'A transaction costs analysis model of channel integration in international markets', Journal of Marketing Research, Vol. 27, No. 2, pp. 196-208.

55 See ref 40 above.

56 ibid.

57 See ref 3 above.

58 See ref 41 above.

59 See ref 23 above.

60 Dillman, D. A. (2000) Mail and Internet Surveys: The Tailored Design Method. John Wiley, New York.

61 Mann, C.and Stewart, F. (2000) Internet Communication and Qualitative Research: A Handbook for Researching Online. Sage Publications, London.

62 Moore, G. C. and Benbasat, I. (1991) 'Development of an instrument to measure the perceptions of adopting an information technology innovation', Information Systems Research, Vol. 2, pp. 192-222.

63 ibid.

64 Churchill Jr., G.A. (1979) ‘A paradigm for developing better measures of marketing constructs', Journal of Marketing Research, Vol. 16, No. 1, pp. 64-73.

65 Venkatraman, N. (1989) 'Strategic orientation of business enterprises: The construct, dimensionality, and measurement', Management Science, Vol. 35, No. 8, pp. 942-963.

66 Hair, J. F., Anderson, R. E. and Tatham, R. L. (1998) Multivariate Data Analysis. 5th edn, Prentice-Hall, Upper Saddle River, New Jersey.

67 Hosmer Jr., D. W. and Lemeshow, S. (1989) Applied Logistic Regression. John Wiley \& Sons, Inc, New York.

68 See ref 5 above. 